\title{
Adsorptive Removal of Malachite Green Dye from Aqueous Solution Using Chemically Modified Charred and Xanthated Wheat Bran
}

\author{
Dilli Dhami ${ }^{1}$, Puspa Lal Homagai*1 \\ ${ }^{1}$ Department of Chemistry, Amrit Science Campus, Tribhuvan University, Kathmandu, Nepal \\ *Corresponding E-mail: homagaipl@gmail.com
}

(Received: March 19, 2020; Revised: June 4, 2020 \& Accepted: June 24, 2020)

\begin{abstract}
Adsorptive removal of Malachite Green (MB) dye from aqueous solution using chemically modified Wheat Bran has been investigated. Wheat bran was chemically modified to charred through charring process and it was further modified to Xanthated through xanthation process. Batch experiments were carried out to study the experimental parameters such as effect of $\mathrm{pH}$, effect of concentration and effect of contact time for both Charred Wheat Bran (CWB) and Xanthated Wheat Bran (XWB) simultaneously. The concentrations of dye ions before and after the adsorption were determined by using UV-Visible Spectrophotometer. The dye uptake was maximum for the initial $\mathrm{pH}$ of 4 for both $\mathrm{CWB}$ and XWB but the percentage removal for XWB was found to be effective in comparison with CWB i.e., $98.45 \%$ and $93.45 \%$ respectively with adsorbent dose of $0.025 \mathrm{~g}$ and agitation speed of $190 \mathrm{rpm}$. The applicability of Langmuir isotherm was tested. The adsorption capacity of MG dye into CWB and XWB was found to be $69 \mathrm{mg} / \mathrm{g}$ and $112.9 \mathrm{mg} / \mathrm{g}$, respectively. Similarly, the kinetic data best fitted for pseudo-second order. Hence, the result showed that XWB may be an attractive alternative for the removal of MG dye from aqueous solution in comparison to CWB as bioadsorbent.
\end{abstract}

Keywords: Malachite green, xanthated wheat bran, adsorption-isotherm, charred wheat bran

\section{Introduction}

Industries like textile, paper, food technology, hair colorings, leather tanning etc. use synthetic dyes extensively. Wastewaters discharged from these industries are usually polluted by residual dyes [1]. Such residual dyes are non-biodegradable due to their complex molecular structures making them more stable and harder to biodegrade. They pollute water, inhibit penetration of sunlight into the water bodies and constitute a serious threat to the environment. Many of them are also toxic in nature and can cause direct destruction or can affect catalytic capabilities of various microorganisms [2].

Malachite green (MG) is available in various forms, namely oxalate or hydrochloride salt [4]. Malachite green a triphenylmethane cationic dye, is most commonly used for dyeing cotton silk, paper, leather and also in manufacturing of paint and printing inks.
[5] In addition, MG also is used as a fungicide and antiseptic in aquaculture industry to control fish parasites and disease [6]. The MG is highly toxic to mammalian cells and causes detrimental effects in liver, kidney, intestine, gonads and pituitary gonadotropic cells. In addition, they may enter into the food chain and could possibly causes carcinogenic, mutagenic, teratogenic effects on humans. Therefore, the treatment of effluent containing MG pollutants being discharged to the environment is essential [7].

Several methods are used to remove these dyes from waste water, namely chemical oxidation and membrane separation. Other processes include aerobic/anaerobic processes, electrochemical method, agglomeration etc. Because of being expensive and inefficient, most of these processes are not used on large scale. Coagulations and chemical and electrochemical oxidations have low practicability on large scale plants. Adsorption is preferable over 
these processes and is widely used because of low cost and high performance. Activated carbon is the most common adsorbent used. Economic benefits, performance efficiencies and environment are primary considerations while choosing an adsorbent, therefore researchers usually cheap and best adsorbents, which are usually waste materials such as activated carbon prepared from the agricultural wastes/by-products such as saw dust, maize cob, rice husk, tea leaves, potato peel, orange peel, coconuts heel, etc. [13]. Hence, herein we report wheat bran as a low cost, ecofriendly, rapid and cost-efficient bio-adsorbent for the removal of malachite green dye.

Wheat bran collected was converted into carbon by the chemical treatments adding conc. sulphuric acid. That charred bio-waste can be further activated by chemical modification. With the help of activation of the surface functional group, adsorption increases gradually.

\section{Materials and Methods Materials}

Wheat bran were collected from Punarbash municipality-09, Kanchanpur Nepal. All chemical used were LA/AR grade.

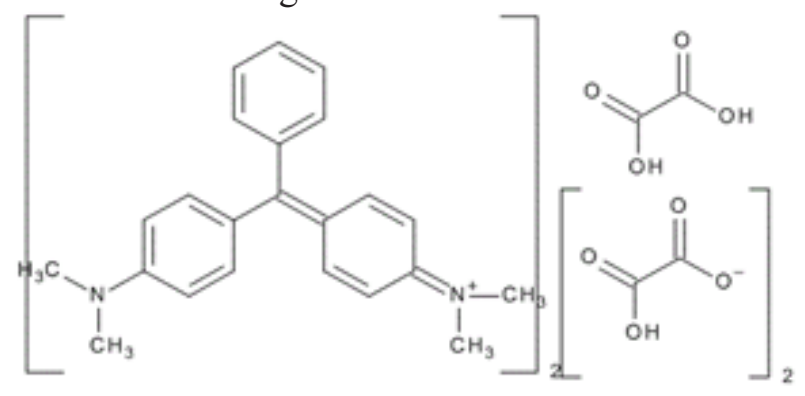

Figure 1: Molecular structure of malachite green.

\section{Preparation of charred wheat bran}

For the preparation of Charred wheat bran, $400 \mathrm{~g}$ of the powered wheat bran was taken in a $5 \mathrm{~L}$ bucket and $100 \mathrm{~mL}$ of conc. sulphuric acid $\left(\mathrm{H}_{2} \mathrm{SO}_{4}\right)$ was added in it and stirred thoroughly with wooden spatula until it turns completely black. Addition of conc. $\mathrm{H}_{2} \mathrm{SO}_{4}$ added in a little amount at first followed by stirring and again added in small amount. This process was repeated several times till it turns completely black in color. This process is called charring. In this process ring opening of cellulose takes place. Thus, obtained black power of wheat bran was left over for $24 \mathrm{hrs}$. Charred sample was washed several times with deionized water until the $\mathrm{pH}$ of the water obtained after washing reached to neutral i.e. $\mathrm{pH} 7$ then it was air dried for 4 days and $6 \mathrm{hrs}$. in hot air oven for complete removal of moisture from it. Thus, obtained charcoal was grinded thoroughly and sieved with $150 \mu \mathrm{m}$. Finally, $200 \mathrm{~g}$ charred sample obtained was kept in desiccator for $1 \mathrm{hr}$ and stored in air tight bottle.

\section{Preparation of xanthated wheat bran}

$100 \mathrm{~g}$ of the charred wheat bran was taken in a reagent bottle, $100 \mathrm{~mL}$ of $1 \mathrm{~N} \mathrm{NaOH}$ was added in it and shaked in a mechanical shaker for 3 hrs. Then $20 \mathrm{~mL}$ of carbon disulphite was added in it and again shaked in mechanical shaker for $6 \mathrm{hrs}$ and left overnight, after which the solution was filtered with Whatman filter paper. It was washed with several times with deionized water for making the sample neutral. Thus, obtained charcoal was air dried for 3 days and oven dried for $6 \mathrm{hrs}$. for complete removal of moisture. Finally, 70 $\mathrm{g}$ Xanthated wheat bran was kept in desiccator for 1 hrand stored in air tight bottle.

\section{Instrumentation}

SEM images of samples were taken to investigate the surface morphology of the activated carbons using FE-SEM, HITACHI, SUB 8230, Tokyo, Japan.The FTIR spectrum of CWB and XWB before and after adsorption of MG dye were analyzed by SHIMADZU, IRPrestige-21, Pacific Commercial Company (P) Ltd.

A calibration curve for MG dye was constructed by using UV-Vis double beam spectrophotometer (Model LT-2802) at maximum wavelength of $617 \mathrm{~nm}$ at $\mathrm{pH} 4$. Similarly, the $\mathrm{pH}$ of the solution was monitored using Digital pH meter, Labtronics-11, Hyderabad, India.

\section{Experimental procedure}

Batch adsorption experiments were carried out in a mechanical shaker at room temperature. $25 \mathrm{~mL}$ of MG dye solution of known concentration (25-800 $\mathrm{mg} / \mathrm{L}$ ) was shaken at constant agitation speed (190 rpm) with constant adsorbent dose $25 \mathrm{mg}$ for specific period of contact time in mechanical shaker. The $\mathrm{pH}$ of the solution was adjusted by contacting with $\mathrm{HCl}$ or $\mathrm{NaOH}$ solution. After equilibrium, the final concentrations $(\mathrm{Ce})$ were measured and the amount of $\mathrm{MG}$ dye adsorbed in $\mathrm{mg} / \mathrm{g}$ at equilibrium was computed by the equation. 


$$
q_{e}=\frac{c_{i}-c_{e}}{W} \times V
$$

where, and are the initial and equilibrium concentration of $\mathrm{MG}$ dye in $\mathrm{mg} / \mathrm{L}$, respectively. $\mathrm{V}$ is volume of $\mathrm{MG}$ dye solution in liter and $\mathrm{W}$ is the weight of adsorbent in gram.

And the percentage adsorption of dye was calculated using the following expression,

$$
\% A=\frac{c_{i}-C_{e}}{W} \times 100
$$

Where $\mathrm{A} \%$ is the percentage of dye adsorption from the solution.

\section{Results and Discussion}

\section{Characterization of adsorbents: FTIR analysis}

The combined FTIR spectrum of RWB, CWB and XWB is shown in the following figure separately. The FTIR spectrum of adsorbents were taken between $300-4500 \mathrm{~cm}^{-1}$ using IR tracer. By the close inspection of FTIR spectrum the samples showed clear and broad centered at $3200-3600 \mathrm{~cm}^{-1}$ which is because of vibrations of $\mathrm{OH}$ groups of alcohols, phenols or carboxylic acids. The band is very intense in RAW and decreased on modified samples.

This means the moisture content after treatment drastically decreased hence, the amount of carbon remains in the sample. The broad peak observed at $3348.42 \mathrm{~cm}^{-1}$ are due o the existence of bounded hydroxyl groups. The peak observed at 2924.09 $\mathrm{cm}^{-1}$ can be assigned to C-H group. The peak around

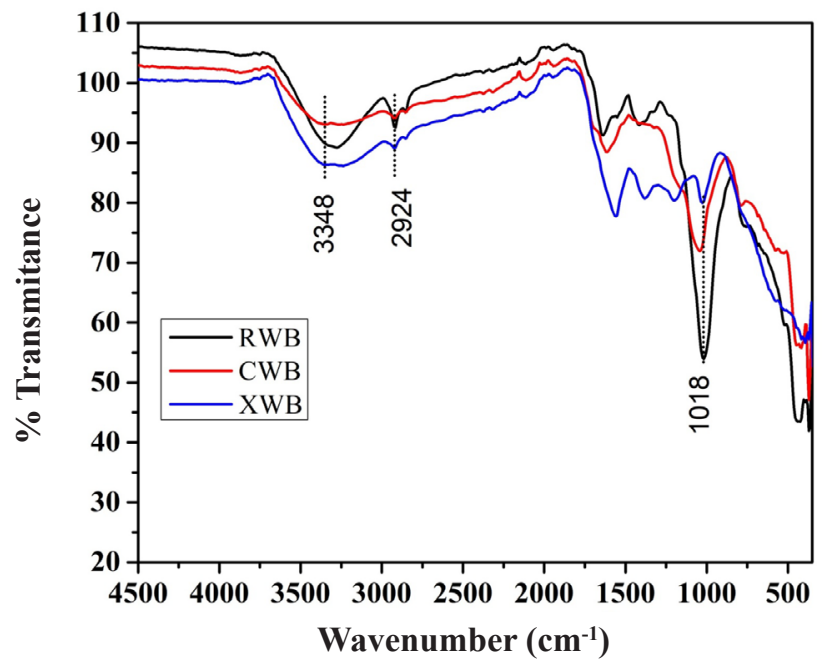

Figure 2: FTIR spectra of $R W B, X W B$ and $C W B$
$1018.41 \mathrm{~cm}^{-1}$ (RWB), $1041.56 \mathrm{~cm}^{-1}$ (CWB) and $1026.13 \mathrm{~cm}^{-1}$ (XWB) are the characteristics of C-O group of primary hydroxyl group also the peaks at $1635 \mathrm{~cm}^{-1}$ (RWB), $1612.49 \mathrm{~cm}^{-1}$ (CWB) and $1558.48 \mathrm{~cm}^{-1}$ (XWB) shows N-H group present at all adsorbent. The sulfate is found between the range of $1380-1415 \mathrm{~cm}^{-1}$ and the result extracted is found the band $1365.60 \mathrm{~cm}^{-1}$ at CWB is depicted to 1381.03 $\mathrm{cm}^{-1}$ revealing that sulfate group.

\section{FE-SEM analysis}

The SEM images of RWB, CWB and XWB are shown in Figure 3a, $3 b$ and $3 c$ respectively. The SEM image of RWB appears to be rough whereas those of CWB and XWB appear to be micro porous, showing high surface area. Surface structure of the XWB was found more enhanced morphology, rough and non-uniform then that of CWB because of the further modification from CWB. Its SEM structure looks like honeycomb with full of cavities having capacity to adsorb more adsorbate in its cavities. SEM images revealed that adsorption capacity of the CWB is less than that of XWB.

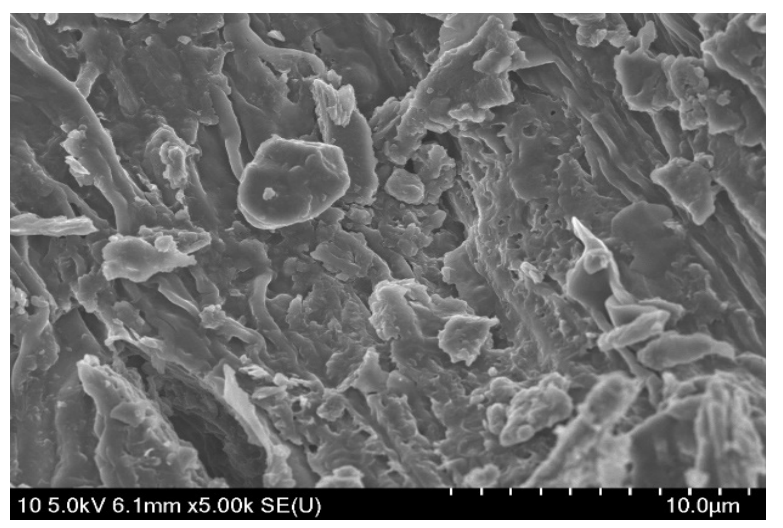

Figure 3a: SEM image of RWB

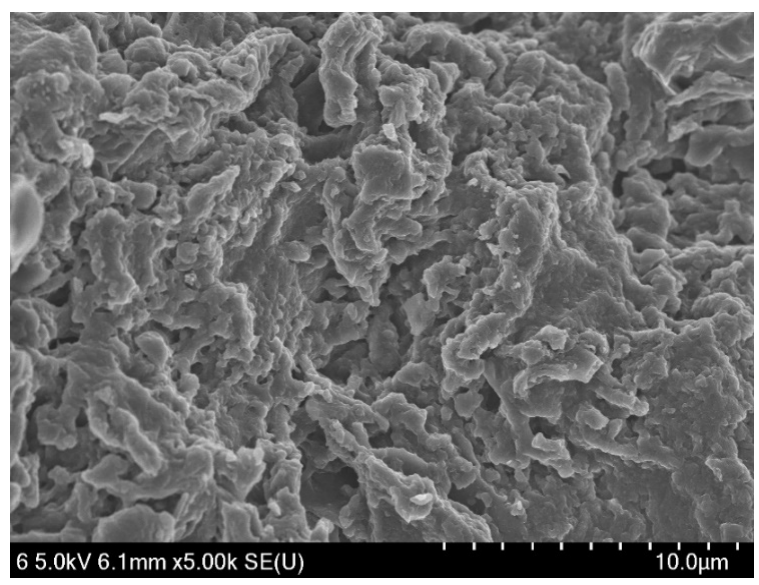

Figure 3b: SEM image of $C W B$ 


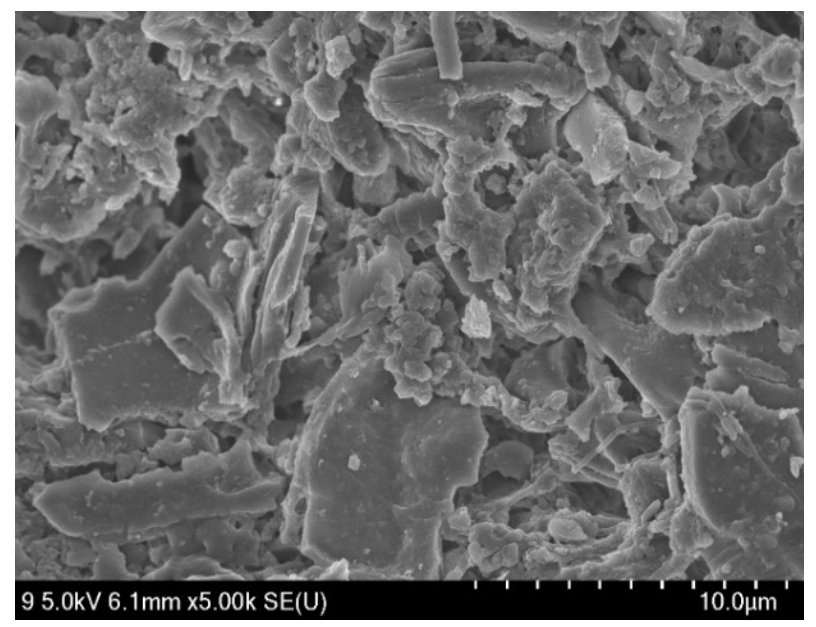

Figure 3c: SEM image of $X W B$

\section{Effect of pH on MG dye removal}

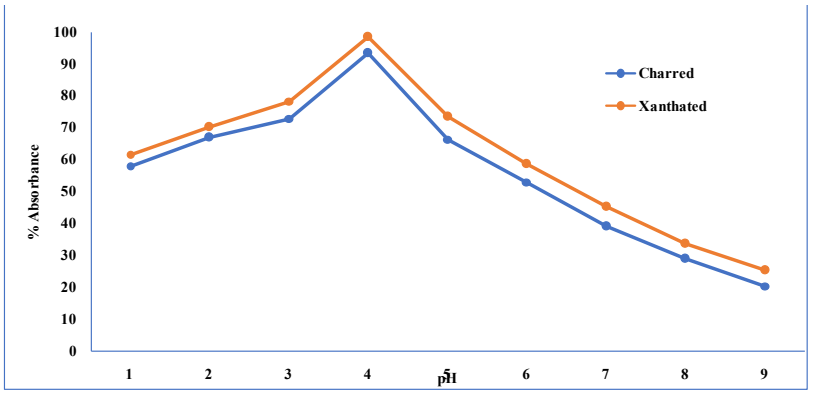

Figure 4: Effect of $p H$ on $C W B$ and $X W B$

From the $\mathrm{pH}$ studies it is seen that the optimum $\mathrm{pH}$ for CWB and XWB was found to be 4.0. It can be seen from above figure that the maximum percentage removal of the MG dye was found to be $93.35 \%$ and $98.45 \%$ for CWB and XWB respectively. The dye removing ability of the XWB was found more efficient than that of the CWB because of the addition of the chelating group i.e. S-atom of sulphur group which enhance the ability of the activated carbon to adsorb more dye onto the XWB. Thus, it can be concluded that the optimum $\mathrm{pH}$ for adsorption of $\mathrm{MG}$ dye by CWB and XWB is 4.0.

\section{Kinetic studies of adsorption of MG dye}

Kinetics studies of the adsorption of MG dye onto CWB and XWB was represented as a function of time at initial dye concentration of $25 \mathrm{ppm}$. The concentration of the dye was analyzed as the function of time at optimum $\mathrm{pH} 4$ by using UV-Visible spectrophotometer. In batch adsorption process, kinetic studies provide information about optimum conditions, mechanism of sorption, and possible rate controlling step. For this purpose, linear and nonlinear form of pseudo-first- and pseudo-secondorder kinetics is applied on adsorption data.

The pseudo-first-order equation is given as:

$$
\log \left(q_{e}-q_{t}\right)=\log q_{e}-\frac{K_{f}}{2.303} t
$$

The value of will be calculated from the linear plot of vs $t$ for the adsorption of dye. Hence, the plot of against $t$ gives the straight line from which and can be calculated from slope and intercept respectively.

The pseudo-second order model is represented as:

$$
\frac{t}{q_{t}}=\frac{1}{k_{s} q_{e}^{2}}+\frac{1}{q_{e}} t
$$

The equilibrium adsorption capacity, is obtained from the slope and is obtained from the intercept of linear plot of $t / q_{t}$ versus $t$.

Pseudo second order plot of t/qt vs time give the perfect straight line for the adsorption of $\mathrm{MG}$ dye onto CWB and XWB simultaneously indicating that the adsorption reaction can be followed from the pseudo order kinetic model. Correlation coefficient $\mathrm{R}^{2}$ value is nearly unity foe both CWB and XWB which shows that the pseudo second order model can be applied for the adsorption of the MG dye onto CWB and XWB

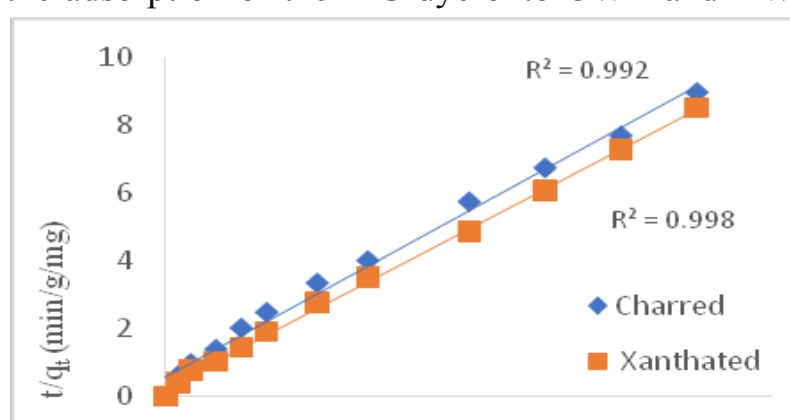

$0 \quad 20 \quad 40 \quad 60 \quad 80100120140160180200220240$

Time (min)

Figure 5: Pseudo-second order kinetic model for the adsorption of $M G$ dye by using $C W B$ and $X W B$

Table 1: Pseudo-second order kinetics for adsorption of $M G$ dye onto $C W B$ and $X W B$

\begin{tabular}{ccc}
\hline Dye (MG) & Slope & $\mathbf{R}^{\mathbf{2}}$ \\
\hline MG onto CWB & 0.0409 & 0.9922 \\
\hline MG onto XWB & 0.0393 & 0.9985 \\
\hline
\end{tabular}


also confirms the chemisorption of dye ions. All the above phenomenon is shown in the fig. below.

\section{Adsorption isotherm studies}

Adsorption isotherm experiment was conducted by taking various amounts of adsorbents in reagent glass bottles. Different amounts of adsorbents were added to each case of dye solution prepared in our laboratory. After an equilibration period of four hours absorbance of the supernatant clear liquid is determined spectrophotometrically at maximum wavelengh of dye. The amount of dye adsorbed was calculated using the graph. The applicability of the isotherms was judged from the values of the correlation coefficient for Freundlich and Langmuir isotherms. The Langmuir equation can be written in the following linear form:

$$
\frac{C_{e}}{q_{e}}=\frac{1}{q_{m} K_{L}}+\frac{C_{e}}{q_{m}}
$$

Where, is the amount of adsorbate per unit mass of adsorbent at equilibrium in $(\mathrm{mg} / \mathrm{g})$, is the equilibrium concentration of adsorbate in $(\mathrm{mg} / \mathrm{L})$, is the maximum adsorption capacity $(\mathrm{mg} / \mathrm{g})$ and is the Langmuir adsorption equilibrium constant $(\mathrm{L} / \mathrm{mg})$. The linear form of the Freundlich isotherm is as follows:

$$
\log q_{e}=\log K_{F}+\frac{1}{n} \log C_{e}
$$

Where, is the amount adsorbed per unit mass of adsorbent $(\mathrm{mg} / \mathrm{g})$, is the equilibrium concentration of the adsorbate $(\mathrm{mg} / \mathrm{L})$. and are Freundlich equilibrium

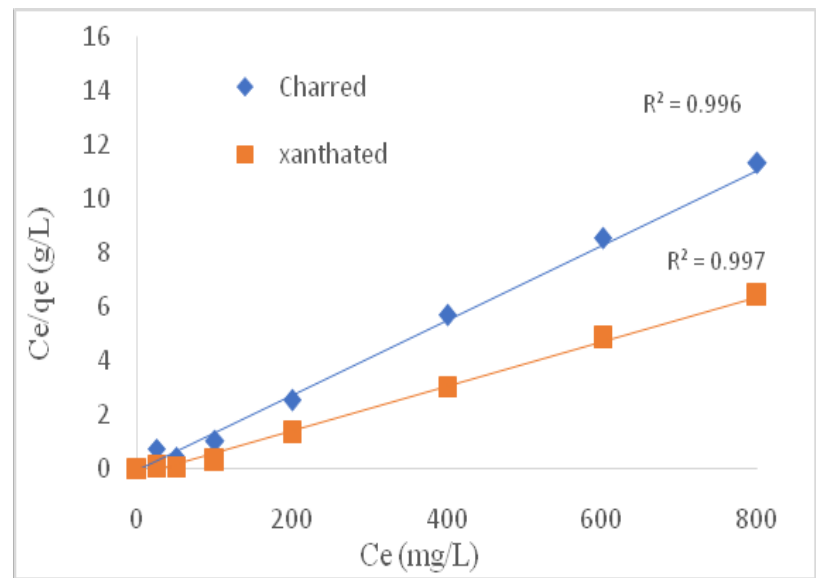

Figure 6: Langmuir plot for the adsorption of $M G$ dye onto $C W B$ and $X W B$ coefficients, which are considered to be the relative indicators of adsorption capacity and adsorption intensity.

Langmuir and Freundlich adsorption isotherm were plotted from the data obtained from the effect of the initial concentration. Among them Langmuir Table 2: Langmuir parameter for the adsorption of $M G$ dye onto $C W B$ and $X W B$

\begin{tabular}{lll}
\hline Dye & $\mathbf{q}_{\mathbf{e}}(\mathbf{m g} / \mathbf{g})$ & $\mathbf{R}^{2}$ \\
\hline MG onto CWB & 69 & 0.9969 \\
\hline MG onto XWB & 112.9 & 0.9971 \\
\hline
\end{tabular}

adsorption isotherm best fitted the by both adsorbents because Langmuir plot have correlation coefficient $\mathrm{R}^{2}$ nearly equal to 1 than that of the Freundlich plot.

\section{Conclusion}

The maximum adsorption of dye was at initial $\mathrm{pH}$ of 4 for both CWB and XWB which illustrate that the optimum $\mathrm{pH}$ for both $\mathrm{CWB}$ and $\mathrm{XWB}$ is $\mathrm{pH} 4$. The percentage of adsorption was found to be $93.35 \%$ and $98.45 \%$ respectively with adsorbent dose of $0.025 \mathrm{~g}$ and agitation speed of $190 \mathrm{rpm}$. Different adsorption isotherms plot was plotted using the data calculated mathematically using the adsorption data obtained from the initial concentration of dye. The data best fitted for the Langmuir isotherm which has higher correlation coefficient for both CWB and XWB i.e. 0.9922 and 0.9985 respectively. Similarly, while studying the effect of contact time; it is concluded that CWB and XWB follows Pseudo-second order kinetics which is also verified by higher correlation coefficient values 0.9969 and 99.71 for CWB and XWB respectively.

Thus, it can be concluded that the CWB and XWB can be used for the adsorption of MG dye from the aqueous solution also XWB may be a better alternative for the removal of $\mathrm{MG}$ dye from aqueous solution in comparison to CWB as bioadsorbent.

\section{Acknowledgement}

Authors would like thank Asst. Prof. Kamal 
Sapkota for FE-SEM analysis and Department of Plant Resources, Thapathali, Kathmandu for FTIR measurement.

\section{References}

1. B. H. Hameed, and M. I. El- Khaiary, Batch removal of malachite green from aqueous solutions by adsorption on oil palm trunk fibre: Equilibrium isotherms and kinetic studies, Journal of Hazardous Materials, 2008, 154, 237244. (DOI: 10.1016/j.jhazmat.2007.10.017).

2. S. Srivastava, R. Sinha, and D. Roy, Toxicological effects of malachite green, Aquatic Toxicology, 2004, 66, 319-329. (DOI: 10.1016/j. aquatox.2003.09.008).

3. A. Mohammedi, H. Daemi, and M. Barikani, Fast removal of malachite green dye using novel superparamagnetic sodium alginate-coated $\mathrm{Fe}_{3} \mathrm{O}_{4}$ nanoparticles, International Journal of Biological Macromolecules, 2014, 69, 447-455. (DOI: 10.1016/j.ijbiomac.2014.05.042).

4. J. Zhang, Z. Zhang, and J. Yuming, Adsorption of malachite green from aqueous solution onto carbon prepared from Arundo donax root, Journal of Hazardous Materials, 2008, 150, 774-782. (DOI: 10.1016/j.jhazmat.2007.05.036).

5. Z. Bekc, S. Yoldas and C. Levent, Removal of malachite green by using an invasive marine alga Caulerpa (racemosa var. cylindracea), Journal of Hazardous Materials, 2009, 161, 1454-1460.

6. E. EI Qada, J. Allen, and M. Walker, Adsorption of basic dyes from aqueous solution onto activated carbons, Chemical Engineering Journal, 2008, 135 174-184. (DOI: 10.1016/j.cej.2007.02.023).

7. B. Dos Santos, A. E. Bisschops, J. Cervantes and B. van Lier, Effect of different redox mediators during thermophilic azo dye reduction by anaerobic granular sludge and comparative study between mesophilic $\left(30^{\circ} \mathrm{C}\right)$ and thermophilic $\left(55^{0} \mathrm{C}\right)$ treatments for decolorization of textile waste waters, Chemosphere, 2004, 55, 1149-1157. (DOI: 10.1016/j.chemosphere.2004.01.031).

8. HO, YS., and G. McKAF, The kinetics of sorption of basic dyes from aqueous solution by sphagnum moss peat, The Canadian Journal of Chemical Engineering, 1998, 76, 822-827. (DOI: 10.1002/ cjce.5450760419).

9. H. Demiral and I. Demiral, Surface properties of activated carbon prepared from wastes, Journal of Surface and Interface Analysis, 2008, 40, 612615. (DOI: 10.1002/sia.2716).

10. V. K. Gupta and S. Suhas, Application of lowcost adsorbents for dye removal, Journal of Environmental Management, 2009, 90, 2313-
2342. (DOI: 10.1016/j.jenvman.2008.11.017)

11. S. Nallusamy and A. M. Babu, X-ray differaction and FESEM analysis for mixture of hybrid nano particles in heat transfer applications, Journal of Nano Research, 2016, 37, 58-67. (DOI: 10.4028/ www.scientific.net/JNanoR.37.58).

12. C. Lopes, P. Limirioa, V. R. Novaisa, and P. Dechichi, Fourier transform infrared spectroscopy (FTIR) application chemical characterization of enamel, dentin and bone, Journal Applied Spectroscopy, 2018, 53, 747-769. (DOI: 10.1080/05704928.2018.1431923).

13. H. Patel, Fixed-bed column adsorption study: a comprehensive review, Applied Water Science, 2019, 34, 9-45. (DOI: 10.1007/s13201-019-0927-7).

14. O. Edokpayi, O. Osemwenkhae, B.V. Ayodele, J. Ossai, S. A. Fadilat, and S.E. Ogbeide, Batch adsorption study of methylene blue in aqueous solution using activated carbons from rice husk and coconut shell, Journal of Applied Sciences and Environmental Management, 2018, 22, 631635. (DOI: 10.4314/jasem. v22i5.4).

15. Si Y. C. Sharma, B. Singh and U. Uma, Fast removal of malachite green by adsorption on rice husk activated carbon, The Open Environmental Pollution \& Toxicology Journal, 2009, 1, 74-78. (DOI: 10.2174/1876397900901010074).

16. S. D. Khattri, and M. K. Singh, Removal of malachite green from dye wastewater using neem sawdust by adsorption, Journal of Hazardous Materials, 2009, 167, 1089-1094. (DOI: 10.1016/j.jhazmat.2009.01.101).

17. V. K. Garg, R. K. Hooda and R. Gupta, Removal of malachite green dye from aqueous solution by adsorption using agro-industry waste: a case study of Prosopis cineraria, Journal of Dyes and Pigments, 2004, 62, 1-10. (DOI: 10.1016/j. dyepig.2003.10.016).

18. A. Ahmad, and R. Kumar, Adsorption studies of hazardous malachite green onto treated ginger waste, Journal of Environmental Management, 2010, 91, 1032-1038. (DOI: 10.1016/j. jenvman.2009.12.016).

19. K. Belay, and M. Abebe, Removal of malachite green from aqueous solutions by adsorption using low cost boisorbent neem leaf (Azadirachta indica), Journal of Environmental Science and Toxicology, 2014, 4, 086-092. (DOI: 10.13140/ RG.2.1.1354.5685).

20. S. Chowdhury, R. Misra, P. Das, and P. Kushwaha, Adsorption thermodynamics, kinetics and isosteric heat of adsorption of malachite green onto chemically modified rice husk, Journal of Desalination, 2011, 265, 159-168. 
(DOI: 10.1016/j.desal.2010.07.047).

21. E. Akar, A. Altinisk, and S. Seki, Using of activated carbon produced from spent tea leaves for the removal of malachite green from aqueous solution, Ecological Engineering, 2013, 52, 1927. (DOI: 10.1016/j.ecoleng.2012.12.032).

22. R. Uma, S. Banerjee, and Y. C. Sharma, Equilibrium and kinetic studies for removal of malachite green from aqueous solution by a low cost activated carbon, Journal of Industrial and Engineering Chemistry, 2013, 19, 1099-1105. (DOI: 10.1016/j.jiec.2012.11.030).

23. R. Malik, D. S. Ramteke, and S. R. Wate, Adsorption of malachite green on groundnut shell waste based powdered activated carbon, Journal of Waste Management, 2007, 27, 1129-1138. (DOI: 10.1016/j.wasman.2006.06.009).

24. M.A. Ahmad, and R. Alrozi, Removal of malachite green dye from aqueous solution using rambutan peel-based activated carbon: Equilibrium, kinetic and thermodynamic studies, Journal of Chemical Engineering Journal, 2011, 171, 510-516. (DOI: 10.1016/j.cej.2011.04.018).

25. T. Robinson, B. Chandran, and P. Nigam, Removal of dyes from a synthetic textile dye effluent by biosorption on apple pomace and wheat straw, Journal of Water Research, 2002, 36, 2824-2830. (DOI: 10.1016/s0043-1354(01)00521-8).

26. M. T. Sulak, E. Demirbas, and M. Kobya, Removal of Astrazon Yellow 7GL from aqueous solutions by adsorption onto wheat bran, Journal of Bioresource Technology, 2007, 98, 2590-2598. (DOI: 10.1016/j.biortech.2006.09.010)

27. X. S. Wang, and X. P. Chen, Biosorption of congo red from aqueous solution using wheat bran and rice bran: batch studies, Journal of Separation Science and Technology, 2009, 44, 1452-1466. (DOI: 10.1080/01496390902766132).

28. B. H. Hameed, and F. M. D. Daud, Adsorption studies of basic dye on activated carbon derived from agricultural waste: Heveabrasiliensis seed coat, Chemical Engineering Journal, 2008, 139, 48-55. (DOI: 10.1016/j.cej.2007.07.089).

29. E. Demirbas, M. Kobya, and M. T. Sulak, Adsorption kinetics of a basic dye from aqueous solutions onto apricot stone activated carbon, Journal of Bioresource Technology, 2008, 99, 5368-5373. (DOI: 10.1016/j. biortech.2007.11.019).

30. A. Saeed, M. W.Akhter, and M. Iqbal, Removal and recovery of heavy metals from aqueous solution using papaya wood as a new biosorbent, Journal of Separation and Purification Technology, 2005, 45, 25-31. (DOI: 10.1016/j.seppur.2005.02.004).
31. S. Wang, Y. Boyjoo, A. Choueib, and Z. H. Zhu, Removal of dyes from aqueous solution using fly ash and red mud, Journal of Water Research, 2005, 39, 129-138. (DOI: 10.1016/j. watres.2004.09.011).

32. W. S. Ngah, and M. A. K. M. Hanafiah, Removal of heavy metal ions from wastewater by chemically modified plant wastes as adsorbents: A review, Journal of Bioresource Technology, 2008, 99, 3935-3948. (DOI: 10.1016/j. biortech.2007.06.011).

33. S. Nethaji, A. Sivasamya, G. Thennarasua, and S. Saravanan, Adsorption of malachite green dye onto activated carbon derived from Borassusaethiopum flower biomass, Journal of Hazardous Materials, 2010, 181, 271-280. (DOI: 10.1016/j.jhazmat.2010.05.008).

34. A. Ozer, and H. B. Pirincci, The adsorption of $\mathrm{Cd}(\mathrm{II})$ ions on sulphuric acid-treated wheat bran, Journal of Hazardous Materials, 2006, B137, 849-855. (DOI: 10.1016/j.jhazmat.2006.03.009).

35. I. D. Mall, V. C. Srivastav, N. K. Agarwal, and I. M. Mishra, Adsorptive removal of malachite green dye from aqueous solution by bagasse fly ash and activated carbon-kinetic study and equilibrium isotherm analyses, Colloids and Surfaces A: Physicochemical Engineering Aspects, 2005, 264, 17-28. (DOI: 10.1016/j.colsurfa.2005.03.027).

36. Y. Bulut, and Z. Baysal, Removal of $\mathrm{Pb}$ (II) from wastewater using wheat bran, Journal of Environmental Management, 2006,78, 107-113. (DOI: 10.1016/j.jenvman.2005.03.010).

37. U. Farooq, J. A. Kozinski, M. A. Khan, and M. Athar, Biosorption of heavy metal ions using wheat based biosorbents: A review of the recent literature, Journal of Bioresource Technology, 2010, 101, 5043-5053. (DOI: 10.1016/j. biortech.2010.02.030).

38. P. L. Homagai, K. N. Ghimire, and I. Inoue, Adsorption behavior of heavy metals onto chemically modified sugarcane bagasse, Journal of Bioresource Technology, 2010, 101, 20672069. (DOI: 10.1016/j.biortech.2009.11.073).

39. B. H. Hameed, A. L. Ahmad, and K. N. A. Latif, Adsorption of basic dye (methylene blue) onto activated carbon prepared from rattan sawdust, Journal of Dyes and Pigments, 2007, 75, 143149. (DOI: 10.1016/j.dyepig.2006.05.039). 